\title{
Effect of continuous versus on-demand treatment of ankylosing spondylitis with diclofenac over 2 years on radiographic progression of the spine: results from a randomised multicentre trial (ENRADAS)
}

\author{
Joachim Sieper, ${ }^{1,2}$ Joachim Listing, ${ }^{2}$ Denis Poddubnyy, ${ }^{1}$ In-Ho Song ${ }^{1,3}$ \\ Kay-Geert Hermann, ${ }^{4}$ Johanna Callhoff, ${ }^{2}$ Uta Syrbe, ${ }^{1}$ Jürgen Braun, ${ }^{5}$ \\ Martin Rudwaleit ${ }^{6}$
}

\begin{abstract}
Handling editor Tore K Kvien
- Additional material is published online only. To view please visit the journal online (http://dx.doi.org/10.1136/ annrheumdis-2015-207897)

${ }^{1}$ Medical Department I, Rheumatology, Charité University Medicine, Campus Benjamin Franklin, Berlin, Germany

${ }^{2}$ German Rheumatology Research Center, Berlin, Germany

${ }^{3}$ Abbvie, Chicago, USA ${ }^{4}$ Department of Radiology, Charité University Medicine Berlin, Germany

${ }^{5}$ Rheumazentrum Herne, Herne, Germany ${ }^{6}$ Department of Internal Medicine and Rheumatology, Klinikum Bielefeld, Bielefeld, Germany
\end{abstract}

\section{Correspondence to} Professor Joachim Sieper, Medical Department I, Rheumatology, Charité University Medicine, Campus Benjamin Franklin, Hindenburgdamm 30, Berlin 12200, Germany; Joachim.sieper@charite.de

Received 7 May 2015 Accepted 13 July 2015 Published Online First 4 August 2015

\section{CrossMark}

\section{SLinked}

- http://dx.doi.org/10.1136/ annrheumdis-2015-208194

To cite: Sieper J, Listing J, Poddubnyy $\mathrm{D}$, et al. Ann Rheum Dis 2016;75: 1438-1443.

\section{ABSTRACT}

Background To date, only a single controlled trial provided evidence that non-steroidal anti-inflammatory drugs (NSAIDs) given continuously reduce radiographic progression compared with an on-demand therapy over 2 years in patients with ankylosing spondylitis (AS). In the current study, we tested whether such an effect of NSAIDs could be confirmed in another randomised trial. Methods Patients with AS were randomised for treatment with either continuous (150 mg/day) or ondemand diclofenac for 2 years. Tumour necrosis factorblocker treatment was not allowed during the entire study period. The primary outcome was the difference in radiographic progression in the spine as measured by the modified Stoke Ankylosing Spondylitis Spine Score (mSASSS) scored by two readers blinded to treatment arm and time point.

Results 62 of 85 patients enrolled in the continuous arm and 60 of 82 enrolled in the on-demand arm completed the study. The mSASSS progression was numerically higher in the continuous group (1.28 (0.7 to $1.9)$ vs $0.79(0.2$ to 1.4$))(p=0.39)$. If only patients were analysed who were either $C$ reactive protein positive or had syndesmophytes at baseline, there was again a higher radiographic progression in the continuous versus the on-demand group: 1.68 (0.7 to 2.6) vs 0.96 (0.0 to $1.9)$ and 2.11 (1.1 to 3.1$)$ vs 0.95 (0.0 to 1.9 ), respectively. There was no difference between the two treatment groups regarding adverse events.

Conclusions In our study, continuous treatment with diclofenac over 2 years did not reduce radiographic progression compared with on-demand treatment in AS. Trial registration numbers EudraCt-no 2007007637-39; ClinicalTrials.gov NCT00715091.

\section{INTRODUCTION}

Ankylosing spondylitis (AS) is part of axial spondyloarthritis ${ }^{1}$ and defined by the presence of structural bone damage visible on X-rays in the sacroiliac joints and/or in the spine. ${ }^{2}$ The development of syndesmophytes in the spine contributes considerably to the restriction of spinal mobility ${ }^{3}$ and function, ${ }^{4}$ especially later in the course of the disease. Thus, next to an effective suppression of inflammation the prevention of structural damage, especially osteoproliferative changes in the spine, is an important treatment target.

While tumour necrosis factor (TNF)-blockers are highly effective for the treatment of signs and symptoms, there is no short-term effect over 2-4 years of anti-TNF treatment on new bone formation in the spine of patients with established AS. ${ }^{5}$ Whether new bone formation can be prevented in case of earlier ${ }^{6}$ or longer ${ }^{7}$ treatment with TNF-blockers has still to be proven. Non-steroidal anti-inflammatory drug (NSAID) treatment is the first-line pharmaceutical therapy in patients with axSpA, based on their good efficacy for signs and symptoms. ${ }^{8}$ Moreover, limited data suggest that NSAIDs may also exhibit a disease-modifying effect in AS. It was already in 1976 that one study reported an inhibitory effect of phenylbutazone on the progression of ossification in a retrospective analysis, ${ }^{9}$ which was confirmed later by a prospective and randomised NSAID trial over 2 years in patients with AS starting with celecoxcib. ${ }^{10}$ In addition, a protective effect of a higher NSAID intake $^{11}$ over time was shown in patients from a prospective spondyloarthritis inception cohort in Germany. ${ }^{12}$ In the trial reported here, we aimed to confirm the inhibitory effect of NSAIDs on osteoproliferation in AS. Since we assumed that such an effect, if true, would represent a class effect rather than an effect of a particular type of NSAID, we used a different but commonly used NSAID, diclofenac, as a starting NSAID.

\section{METHODS}

\section{Patients and study design}

The Effects of NSAIDs on RAdiographic Damage in Ankylosing Spondylitis (ENRADAS) study was a prospective randomised controlled trial conducted in 19 centres in Germany between May 2008 and December 2013 (EudraCT 2007-007637-39). Patients aged 18-65 years fulfilling the 1984 modified New York criteria were eligible if they had active disease (back pain on a 0-10 numerical rating scale $\geq 4$ ) that justified the start or continuation of an NSAID and had no contraindications for an NSAID therapy. TNF-blocker treatment was not allowed before and during the whole study. Proton pump inhibitor (PPI) could be added to the 
treatment. Plain radiographs of the cervical and lumbar spine had to be available to allow for randomisation. In order to reduce radiation exposure, existing radiographs of the spine were taken as baseline radiographs if not older than 24 months. Initially, we aimed to restrict the inclusion to patients with AS with at least one syndesmophyte at baseline in order to select for patients with a higher risk for radiographic progression. For feasibility reasons, however, this inclusion criterion was later omitted. The history or presence of gastroduodenal ulcers, chronic inflammatory bowel disease, cardiovascular disease (coronary heart disease, heart failure, stroke or transient ischaemic attack), renal insufficiency and known severe hypersensitivity reactions to NSAIDs were exclusion criteria.

Patients were stratified according to the time period between radiographic examination and inclusion into the trial, resulting in the following groups: $\leq 3$ months $n=115,4-6$ months $n=25,7-$ 9 months $n=20,10-12$ months $n=5$ and $13-15$ months $n=2$.

Using a block randomisation method, patients were randomised within these strata in a 1:1 ratio to treatment with diclofenac either continuously (at least $50 \%$ per day of the maximally recommended daily dose of $150 \mathrm{mg}$ diclofenac) or on demand for a total period of 2 years, without a washout period for previous NSAID treatment. Each pill contained $75 \mathrm{mg}$ of diclofenac. Switching to another NSAID was allowed in case of intolerance or inefficacy. In switchers, equivalent dosages of NSAIDs were used. ${ }^{11}$

\section{Outcome measures}

Primary outcome was spinal radiographic progression assessed by the change in the modified Stoke Ankylosing Spondylitis Spine Score (mSASSS), ${ }^{13}$ which is largely but not exclusively driven by new bone formation. X-rays of the spine (cervical and lumbar spine at baseline and after 2 years of follow-up) were performed locally. The images were centrally collected, digitised, anonymised and subsequently scored independently by two trained readers (DP and K-GH). The readers scored radiographs in a concealed and randomly selected order and were blinded to treatment assignment and all clinical data. The treating physicians were not blinded for treatment arms. The mean of the mSASSS scores of both readers was used in the statistical analysis. Up to eight missing values for vertebral edges at baseline were substituted with the value of this edge at year 2 and vice versa.

\section{Calculation of the NSAID intake}

Data on NSAID intake (dose and frequency) were collected at baseline and every 12 weeks thereafter during 2 years of follow-up. The NSAID intake index ${ }^{11}$ is recommended by the Assessment of SpondyloArthritis international Society (ASAS) and accounts for both dose and duration of drug intake over the whole period of interest (0: no NSAIDs intake at all; 100: daily NSAIDs intake in a dose equivalent to diclofenac $150 \mathrm{mg}$ ). At each study visit, a pill count was performed by the study nurse and checked against patients documented NSAID use in a patient diary.

\section{Statistical analysis}

Based on an mSASSS progression of $1.5 \pm 2.5$ points in the on-demand group and of $0.4 \pm 1.7$ in the continuous treatment group in the Wanders et al ${ }^{10}$ study and assuming a dropout rate of $30 \%$, a sample size of $n=87$ patients per group was calculated. This sample size ensured an $80 \%$ power to detect a similar difference in progression with a two-sided $\alpha$ level of $5 \%$ by means of the Mann-Whitney test or the Welch Satterthwaite t test. The Mann-Whitney test was applied to compare the primary outcome (radiographic progression) in patients with complete sets of radiographs at baseline and at 2 years. To account for differences in the mSASSS baseline status and the dependency of radiographic progression on the status at baseline, a non-parametric analysis of variance test for longitudinal data as proposed by Brunner et $a l^{14}$ was applied in addition. Furthermore, a generalised linear mixed model (GLM) approach was applied to take a possible bias caused by dropouts into account and to compare radiographic progression between the intention-to-treat (ITT) groups. GLMs were also applied to estimate baseline-adjusted mean changes and their 95\% CIs. Although we expected continuous treatment to have greater effects than on-demand treated, we could not be certain. Therefore, all tests applied were two-sided tests. p Values $<0.05$ were considered to be statistically significant.
Figure 1 Flow chart of patients enrolled into the study.
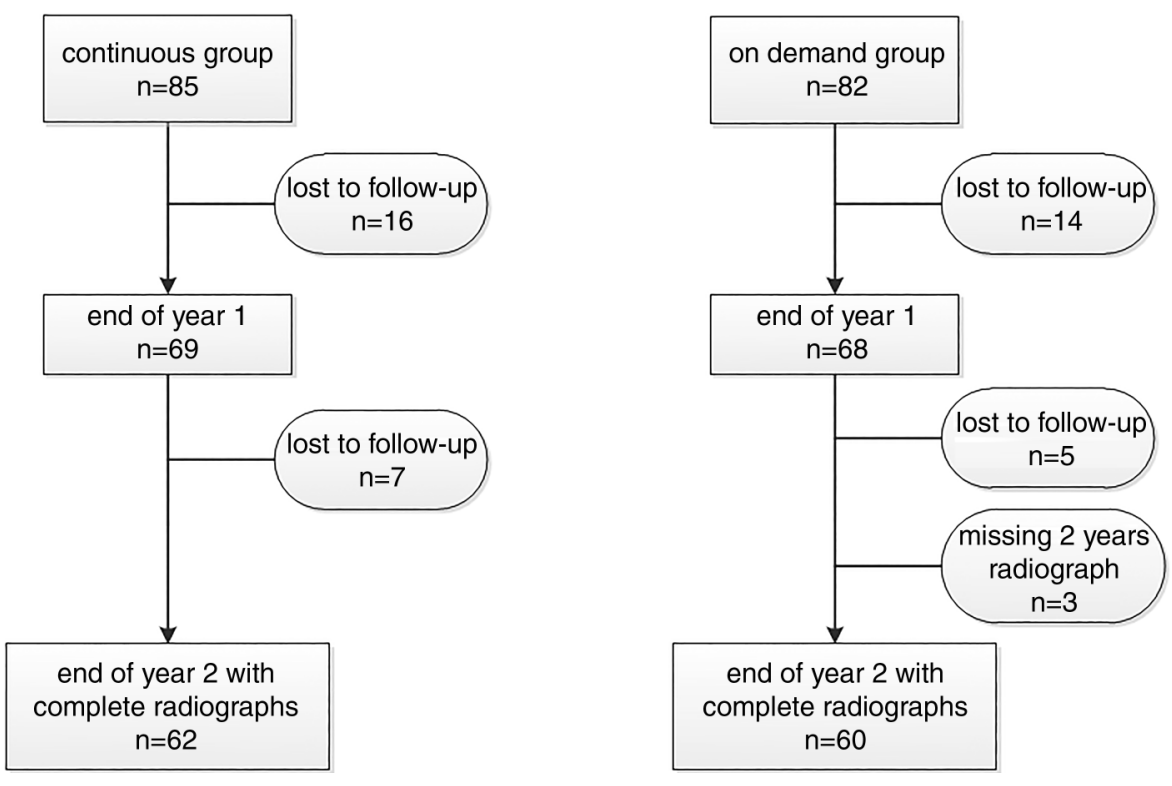
Table 1 Patient characteristics at baseline

\begin{tabular}{|c|c|c|c|c|}
\hline & \multicolumn{2}{|c|}{ Patients with complete sets of radiographs } & \multicolumn{2}{|l|}{ All patients } \\
\hline & Continuous $(n=62)$ & On demand $(n=60)$ & Continuous $(n=85)$ & On demand $(n=82)$ \\
\hline Age, mean (SD) & $40.7(9.6)$ & $45(10.4)^{*}$ & $41.7(10.4)$ & $43.8(10.8)$ \\
\hline Males, n (\%) & $44(71.0)$ & $40(66.7)$ & $63(74.1)$ & $56(68.3)$ \\
\hline Disease duration in years, mean (SD) & $12.8(11.3)$ & $17.0(12.6)^{*}$ & $12.2(10.3)$ & $15.2(12.4)$ \\
\hline HLA-B27 positive, $n(\%)$ & $55(88.7)$ & $55(91.7)$ & $71(83.5)$ & $68(84)$ \\
\hline BASDAl, mean (SD) & $4.1(1.5)$ & $4.2(1.5)$ & $4.2(1.6)$ & $4.5(1.6)$ \\
\hline BASFI, mean (SD) & $2.9(2.1)$ & $3.7(2.2)^{*}$ & $3.1(2.2)$ & $3.9(2.2)^{*}$ \\
\hline ASDAS (CRP), mean (SD) & $2.7(0.7)$ & $2.8(0.7)$ & $2.7(0.8)$ & $2.9(0.8)$ \\
\hline CRP, mg/L, mean (SD) & $7.8(7.4)$ & $12.5(15.1)$ & $8.4(8.1)$ & $12.9(15.5)$ \\
\hline CRP>5 mg/L, $\mathrm{n}(\%)$ & $33(54.1)$ & $35(58.3)$ & $46(55.4)$ & $47(57.3)$ \\
\hline BASMI, mean (SD) & $2.1(2.1)$ & $3(2.3)$ & $2.2(2.1)$ & $2.7(2.2)$ \\
\hline mSASSS, mean (SD) & $10.9(15.5)$ & $16.4(18.2)$ & $11.3(14.9)$ & $14.0(16.8)$ \\
\hline Patients with syndesmophytes at baseline, $n$ (\%) & $33(53.2)$ & $37(61.7)$ & $47(55.3)$ & $47(57.3)$ \\
\hline Current smoker, n (\%) & $36(59)$ & $20(33.3)^{*}$ & $44(52.4)$ & $33(40.2)$ \\
\hline Previous smoker $\mathrm{n}(\%)$ & $14(22.6)$ & $20(33.3)$ & $19(22.4)$ & $23(28.0)$ \\
\hline
\end{tabular}

Values are means (SDs) if not otherwise specified.

* Significant differences $(p<0.05)$ between treatment groups.

ASDAS, Ankylosing Spondylitis Disease Activity Score; BASDAI, Bath Ankylosing Spondylitis Disease Activity Index; BASFl, Bath Ankylosing Spondylitis Functional Index; BASMI, Bath

Ankylosing Spondylitis Metrology Index; CRP, C reactive protein; HLA, human leucocyte antigen; mSASSS, modified Stoke Ankylosing Spondylitis Spine Score.

\section{RESULTS}

Nineteen German centres participated and enrolled at least one patient. In total, 167 of 180 randomised patients were enrolled, 85 patients in the continuous and 82 patients in the on-demand group. Also, 62 of the continuous and 60 patients of the on-demand group completed the 2-year treatment period and had X-rays before and at the end of the period available for analysis (figure 1). Among the 45 patients who did not complete the study, only 2 patients were switched to TNF inhibitors.

There were no clear differences in most of the baseline characteristics between the patients enrolled and the patients with complete sets of radiographs (table 1).

The mean ASAS NSAID index (on a scale between 0 and 100), reflecting NSAID consumption over 2 years, was 76 for the continuous and 44 for the on-demand group. The distribution for the NSAID index is shown for both groups in figure 2. At the end of year 2, 77\% of the completers were still on diclofenac and had not switched to another NSAID.

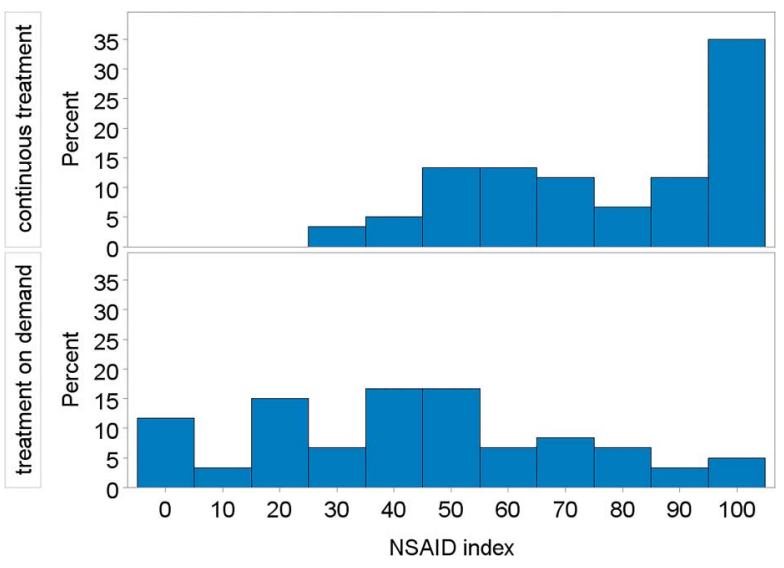

Figure 2 Frequency of non-steroidal anti-inflammatory drug (NSAID) index categories by treatment groups (patients with complete sets of radiographs), calculated according to ref. 11. For two patients in the continuous treatment group, the NSAID index is missing.
Corrected for baseline, the mean Bath Ankylosing Spondylitis Disease Activity Index (BASDAI) values decreased within the completer population during 2 years of treatment to 2.7 in the continuous group and to 3.2 in the on-demand group, confirming indirectly that indeed patients in the continuous group were treated with a higher NSAID dosage.

There was a significant mSASSS progression within both treatment groups (Brunner test $\mathrm{p}=0.00011)$. The mSASSS progression was numerically higher in the continuous group compared with the on-demand group $(1.3 ; 95 \%$ CI 0.7 to 1.9 vs $0.8 ; 95 \%$ CI 0.2 to 1.4 ), although this difference was not statistically significant (figure 3 and table 2) (Mann-Whitney test $\mathrm{p}=0.86$, Brunner test (taking baseline differences into account) $\mathrm{p}=0.39$ ). This finding, based on patients with complete sets of radiographs, was confirmed by a GLM approach, which included the whole ITT population. Since the mean radiographic progression adjusted for baseline was very similar in the ITT population compared with the completer population, a selection bias caused by dropouts can be ruled out. When only patients were analysed who were $\mathrm{C}$ reactive protein (CRP) positive at baseline (54\% continuous, $58 \%$ on demand) or had syndesmophytes at baseline (55\% continuous, $57 \%$ on demand), both known risk

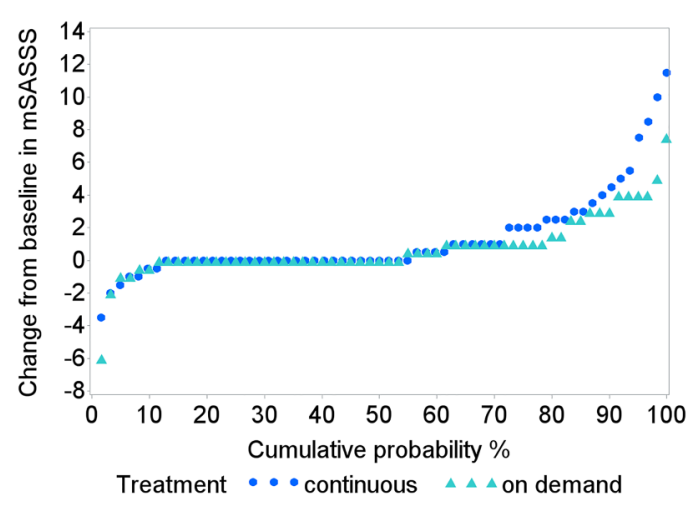

Figure 3 Cumulative probability plot of radiographic progression; mSASSS, modified Stoke Ankylosing Spondylitis Spine Score. 
Table 2 Modified Stoke Ankylosing Spondylitis Spine Score at baseline and end of year 2; baseline-adjusted mean changes for patients with complete sets of radiographs and patients of the intention-to-treat (ITT) population

\begin{tabular}{|c|c|c|c|c|c|}
\hline & \multicolumn{4}{|c|}{ Patients with complete sets of radiographs } & \multirow{2}{*}{$\begin{array}{l}\text { ITT population } \\
\text { Mean change from baseline } \\
(95 \% \mathrm{Cl}) \text { adjusted for baseline status }\end{array}$} \\
\hline & n & Baseline & Year 2 & $\begin{array}{l}\text { Mean change from baseline } \\
(95 \% \mathrm{Cl}) \text { adjusted for baseline status }\end{array}$ & \\
\hline Continuous treatment & 62 & $10.9(15.5)$ & $12.2(16.7)$ & $1.28(0.7$ to 1.9$)$ & $1.29(0.7$ to 1.9$)$ \\
\hline On-demand treatment & 60 & $16.4(18.2)$ & $17.2(18.6)$ & $0.79(0.2$ to 1.4$)$ & $0.71(0.1$ to 1.3$)$ \\
\hline$p$ Value for differences between both groups & & 0.10 & 0.13 & 0.39 & 0.16 \\
\hline \multicolumn{6}{|l|}{ Only patients with syndesmophytes at baseline } \\
\hline$p$ Value for differences between both groups & & 0.08 & 0.16 & 0.10 & 0.07 \\
\hline \multicolumn{6}{|l|}{ Only patients with $\mathrm{CRP}>5 \mathrm{mg} / \mathrm{L}$ at baseline } \\
\hline Continuous treatment & 34 & $13.9(17.9)$ & 15.6 (19.6) & $1.68(0.7$ to 2.6$)$ & $1.67(0.7$ to 2.6$)$ \\
\hline On-demand treatment & 35 & $19.3(19.0)$ & $20.3(19.3)$ & $0.96(0.0$ to 1.9$)$ & $0.84(0.1$ to 1.7$)$ \\
\hline $\mathrm{p}$ Value for differences between both groups & & 0.20 & 0.22 & 0.28 & 0.20 \\
\hline
\end{tabular}

CRP, C reactive protein.

factors for radiographic progression, again there was numerically even a higher radiographic progression in the continuous versus the on-demand group: 1.7 vs 0.8 and 2.1 vs 0.9 , respectively (table 2). The results were also similar when we adjusted for smoking status (data not shown).

We also analysed the mSASSS progression rate according to the NSAID intake using the ASAS NSAID index, independently of the treatment group to which patients were allocated. The mSASSS increase was 0.7 in patients with an NSAID index $<50$ $(n=65)$ and 1.2 in patients with an index $\geq 50 \quad(n=94)$ (difference not significant), also confirming that in this study NSAID treatment did not prevent osteoproliferation. A similar result was seen when the patients were split into those with an NSAID index $<25(n=23)$ and those with $\geq 75(n=53)$ : increase of mSASSS from 12.1 to 12.6 (difference of 0.5 ) versus an increase from 12.0 to 13.1 (difference 1.1 ), respectively. When only considering the formation of new or fused syndesmophytes (ie, mSASSS increase at the single vertebral edges from 0 or 1 to 2 or 3 , or from 2 to 3 ), there was a total increase of 34 vertebral edges with such changes in the continuous group and an increase of 17 vertebral edges in the on-demand group, again rather less progression in the on-demand than in the continuous group. The maximum mSASSS at baseline was 58 (out of 72 possible scoring points), excluding a potential ceiling effect in our study population. There was also no change in the results when we excluded $10 \%$ of the patients with the highest baseline mSASSS (data not shown).

The intraclass correlation coefficient (ICC) for the reading between the two readers was good: 0.96 for baseline X-rays and 0.95 at year 2 , the ICC for the change in mSASSS was 0.50 . The results of radiographic progression were similar when the two $\mathrm{X}$-ray readers were analysed separately. Changes in mSASSS scores in the continuous versus the on-demand group were 1.2 vs 0.9 and 1.3 vs 0.6 for reader 1 and reader 2 , respectively.

Given that baseline syndesmophytes, ${ }^{15}$ elevated baseline $\mathrm{CRP}^{16}$ and smoking ${ }^{16}$ are predictors of radiographic progression, we also analysed the progression rate in these subgroups independently of the NSAID intake to exclude a systematic error, either in our analyses or the database. The mSASSS increase was indeed dependent on the number of syndesmophytes and on elevated CRP at baseline and numerically also on the smoker status (see online supplementary table S1).

\section{Adverse events}

There were no differences between the two treatment groups regarding adverse effects (AEs): there was a similar number of AEs in both groups (data not shown) and a similar number of serious adverse events (SAEs) (table 3). Two myocardial infarctions occurred in the continuous group (male, 51 years, event 1 month after end of study, relationship regarded as unlikely; male, 44 years, event 3 months after end of study, regarded as not related) and one in the on-demand group (male, 53 years, event occurred during the study period but no NSAID intake in the 5 months before the event, regarded as not related).

Table 3 Number of serious adverse events (SAE) and SAE/100 patient years (pyrs) by treatment group $(95 \% \mathrm{Cls}$ are given in parenthesis)

\begin{tabular}{|c|c|c|c|c|}
\hline & \multicolumn{2}{|c|}{$\begin{array}{l}\text { Continuous treatment } \\
\text { group }\end{array}$} & \multicolumn{2}{|c|}{$\begin{array}{l}\text { On-demand treatment } \\
\text { group }\end{array}$} \\
\hline & SAE & SAE/100 pyrs & SAE & SAE/100 pyrs \\
\hline $\begin{array}{l}\text { Cardiovascular disorders } \\
\text { (total) }\end{array}$ & 3 & 2.3 (0.5 to 6.6$)$ & 2 & $1.5(0.2$ to 5.4$)$ \\
\hline Angina pectoris & & & 1 & 0.8 (0 to 4.2 ) \\
\hline Myocardial infarction & 2 & $1.5(0.2$ to 5.4$)$ & 1 & 0.8 (0 to 4.2 ) \\
\hline $\begin{array}{l}\text { Wolff-Parkinson- } \\
\text { White syndrome }\end{array}$ & 1 & 0.8 (0 to 4.2 ) & & \\
\hline $\begin{array}{l}\text { Gastrointestinal disorders } \\
\text { (total) }\end{array}$ & 1 & $0.8(0$ to 4.2$)$ & 7 & $5.3(2.1$ to 10.8$)$ \\
\hline Colitis & 1 & 0.8 (0 to 4.2 ) & 1 & 0.8 (0 to 4.2 ) \\
\hline Crohn's disease & & & 2 & $1.5(0.2$ to 5.4$)$ \\
\hline Diarrhoea & & & 1 & 0.8 (0 to 4.2 ) \\
\hline Diverticulum & & & 1 & 0.8 (0 to 4.2$)$ \\
\hline Inguinal hernia & & & 1 & 0.8 (0 to 4.2 ) \\
\hline Pancreatitis acute & & & 1 & 0.8 (0 to 4.2$)$ \\
\hline $\begin{array}{l}\text { Renal and urinary } \\
\text { disorders (total) }\end{array}$ & 1 & $0.8(0$ to 4.2$)$ & 2 & $1.5(0.2$ to 5.4$)$ \\
\hline Calculus ureteric & 1 & 0.8 (0 to 4.2$)$ & & \\
\hline Nephrolithiasis & & & 2 & $1.5(0.2$ to 5.4$)$ \\
\hline Other SAE & 14 & $10.6(5.8$ to 17.8$)$ & 10 & 7.5 (3.6 to 13.8$)$ \\
\hline SAE total & 19 & 14.4 (8.7 to 22.5$)$ & 21 & 15.8 (9.8 to 24.1$)$ \\
\hline
\end{tabular}

Bold typeface indicates no significance for the differences between the two groups for any of the side effects. 


\section{DISCUSSION}

In this randomised trial, we investigated whether continuous versus on-demand treatment with NSAIDs over 2 years has an inhibitory effect on new bone formation in the spine of patients with AS, as reported before. ${ }^{9} 1012$ However, no such effect could be detected. In fact, we even found a numerically greater reduction of new bone formation in the on-demand group, even though this group was slightly enriched for parameters predictive of new bone formation such as syndesmophytes ${ }^{15}$ and elevated $\mathrm{CRP}^{16}$ at baseline. Only current smoking, also a predictor of radiographic progression, ${ }^{16}$ was found more frequently in the continuous group. When we stratified for patients with syndesmophytes at baseline or elevated CRP only or smoking status only, again on-demand NSAID treatment was associated with numerically less progression than continuous NSAID treatment. Thus, not even in the subgroup of patients with an elevated CRP an effect of continuous NSAID treatment became evident, which is in contrast to the previous celecoxib study by Wanders et al, where a preventive effect of continuous treatment was found only in patients with elevated time-averaged CRP but not in CRP-negative patients. ${ }^{17}$ Since not even a trend for less radiographic progression was seen for the continuous group in our study, it is rather unlikely that inclusion of more patients would have changed the result. MRI of the spine was not performed; therefore, we cannot correlate active inflammation seen on MRI, which has also been discussed as a risk factor, ${ }^{18}$ with radiographic progression.

The lack of efficacy could not be attributed to NSAID dosage as patients in the continuous group were indeed treated with a higher NSAID dose as shown by an ASAS NSAID index of 75 (equivalent of $112.5 \mathrm{mg}$ diclofenac daily over 2 years) compared with an ASAS NSAID index of 44 (equivalent of $66 \mathrm{mg}$ diclofenac daily over 2 years). Furthermore, the lower BASDAI in the continuous group after 2 years of treatment provides indirect evidence that the NSAID intake in the continuous group was indeed greater.

The result of our study is in contrast to three other published reports on the effects of NSAIDs on radiographic progression in AS, two of which are observational studies only. ${ }^{9} 1012$ The phenylbutazone study ${ }^{9}$ was a retrospective analysis only with a rather small number of patients, and the results from the German inception cohort were also based on a rather small number of patients and did not have a control group. ${ }^{12}$ Thus, the main trial to compare our study with is the prospective randomised trial by Wanders et al. ${ }^{10}$ While in our study all patients started on diclofenac, in the study by Wanders et al all patients started on celecoxib. Different dosages in our study and the Wanders study cannot explain the divergent results: the mean daily dose of celecoxib was $243 \mathrm{mg}$ in the continuous-treatment group and $201 \mathrm{mg}$ in the on-demand group in the Wanders study, an even smaller dosage difference between the two groups than in our study (diclofenac $112 \mathrm{mg}$ vs $66 \mathrm{mg}$ ).

A major difference between the two studies is the type of NSAID used for treatment throughout the 2-year period. While both studies allowed patients to switch NSAIDs, $77 \%$ of our patients completed the trial on diclofenac and $65 \%$ of patients completed on celecoxib in the Wanders study. When we designed our trial, we assumed a class effect of NSAIDs on bone formation in AS. Thus, retardation of the new bone formation had been related to COX-2 inhibition, and since in therapeutic concentrations all NSAIDs inhibit COX-2 to nearly the same extent, independently of their COX-selectivity, no substantial difference was expected between different NSAIDs. ${ }^{19}$ Moreover, retardation of bone fracture healing has also been described for diclofenac in a rat model. ${ }^{20}$

The inhibitory effect of NSAIDs on bone formation has been linked to their capabilities to impair the production of prostaglandin E2 (PGE2), which, apart from its proinflammatory activity, enhances bone resorption by promoting osteoclast activity but which can also promote bone formation by stimulating proliferation and activity of osteoblasts. However, differences of COX-2 selective and non-selective COX inhibitors on reparative bone formation, for instance in fracture healing, have been described. In several models of fracture healing, celecoxib and rofecoxib showed stronger impairment of fracture healing than indomethacin. $^{21}$ However, there was no clear difference between celecoxib and indomethacin in the prevention of heterotopic ossification after total hip replacement in one investiga$\operatorname{tion}^{22}$ while in another study celecoxib was superior to ibuprofen for the same indication. ${ }^{23}$

Most interestingly, selective effects of celecoxib are also suspected for osteoarthritis (OA). ${ }^{24}$ In OA, celecoxib but not nonselective COX inhibitors such as diclofenac and naproxen increased the proteoglycan synthesis of OA cartilage. ${ }^{25}$ Additionally, celecoxib but not non-selective COX inhibitors were found to induce apoptosis in osteoblasts ${ }^{26}$-an activity that could be relevant in bone formation in AS. But there is also accumulating evidence that celecoxib also affects signalling pathways independent of COX-2 and PGE2 inhibition. ${ }^{27}$ Coxibs are structurally different from non-selective COX inhibitors, and in particular, their anticancerogenic activity has been attributed to COX-2 independent activity. ${ }^{28}$ Such COX-2 independent activities that primarily affect cell proliferation and survival might result in different effects on joint remodelling including new bone formation. Currently, very limited data are available on this. Our data should stimulate future research addressing the question whether NSAIDs and Coxibs differ in their effect on new bone formation. Alternatively, if these drugs do not clearly differ, the contrasting results from the two clinical trials might indicate that the effect of NSAIDs/coxibs on new bone formation in AS is not as clear as has been postulated.

There were no differences in AEs between the two treatment groups. There was no SAE affecting the upper gastrointestinal tract and no case of acute liver or kidney toxicity (table 3). Three myocardial infarctions occurred in patients who were not on drug in the on-demand group or after the end of the study and were regarded as not to be related to treatment by the local investigators. We have argued before in favour of a positive benefit/risk ratio for the treatment of AS with NSAIDs, mostly based on the good efficacy on signs and symptoms. ${ }^{29}$ However, the number of patients treated in the current study and the lack of a control group without NSAID treatment does not allow firm conclusions about potential side effects.

Acknowledgements We like to thank the participating patients and study centres: PD Dr J. Brandt-Jürgens, Dr K. Karberg, Berlin; Dr S. Jacki, Tübingen; Dr N. Rinaldi, Ulm; Professor K. Manger, Bamberg; Dr W. Ochs, Bayreuth; Professor H. Kellner, München; Dr K-H. Göttl, Passau; Dr R. Dockhorn, Weener; Dr U. Schoo, Rheine; Dr F. Heldmann, Herne; Dr D. Pick, Grafschaft Bad Neuenahr-Ahrweiler; Dr A. Gräßler, Pirna; Dr C. Kühne, Haldensleben, Dr F. Mielke, Berlin, Dr T. Schneider-Stiebler, Wismar, Professor C. Kneitz, Rostock. Special thanks to Renate Lies, lead study nurse, who communicated intensely with the participating study centres throughout the study and was responsible for collection of all study data and material. Further thanks to Beate Buss who provided additional study nurse support. We also like to thank the external members of the Data and Safety Monitoring Board (DSMB) Professor Désirée van der Heijde, Leiden, The Netherlands, Professor Bernhard Manger, Erlangen, Germany, and Dr Wolfgang Bolten, Wiesbaden, for their expert advice. 
Contributors All authors contributed to acquisition, analysis and interpretation of the data and drafting the manuscript.

Funding This clinical trial was funded by the Bundesministerium für Bildung und Forschung (BMBF)/Deutsches Luft- und Raumfahrtzentrum (DLR) as part of a special public funding programme for the conduct of clinical trials in Germany, FKZ 01KG0801. The initial study drug diclofenac was provided by Novartis. We would like to thank Novartis for this study support.

Competing interests I-HS is now an employee of Abbvie but was an employee of the Charite during the time the study was conducted. The initial study drug diclofenac was provided by Novartis, but Novartis did not have any influence on the design, conduct and analysis of the trial.

Patient consent Obtained.

Ethics approval The study protocol was approved by the ethics committee of the federal state Berlin, Germany.

Provenance and peer review Not commissioned; externally peer reviewed.

\section{REFERENCES}

1 Rudwaleit M, van der Heijde D, Landewe R, et al. The development of Assessment of SpondyloArthritis international Society classification criteria for axial spondyloarthritis (part II): validation and final selection. Ann Rheum Dis 2009;68:777-83.

2 van der Linden S, Valkenburg HA, Cats A. Evaluation of diagnostic criteria for ankylosing spondylitis. A proposal for modification of the New York criteria. Arthritis Rheum 1984;27:361-8.

3 Machado $\mathrm{P}$, Landewe $\mathrm{R}$, Braun J, et al. Both structural damage and inflammation of the spine contribute to impairment of spinal mobility in patients with ankylosing spondylitis. Ann Rheum Dis 2010;69:1465-70.

4 Landewe R, Dougados M, Mielants $\mathrm{H}$, et al. Physical function in ankylosing spondylitis is independently determined by both disease activity and radiographic damage of the spine. Ann Rheum Dis 2009;68:863-7.

5 Braun J, Sieper J. Ankylosing spondylitis. Lancet 2007;369:1379-90.

6 Haroon N, Inman RD, Learch TJ, et al. The impact of tumor necrosis factor alpha inhibitors on radiographic progression in ankylosing spondylitis. Arthritis Rheum 2013:65:2645-54.

7 Baraliakos $\mathrm{X}$, Haibel $\mathrm{H}$, Listing J, et al. Continuous long-term anti-TNF therapy does not lead to an increase in the rate of new bone formation over 8 years in patients with ankylosing spondylitis. Ann Rheum Dis 2014;73:710-15.

8 Braun J, van den Berg R, Baraliakos X, et al. 2010 update of the ASAS/EULAR recommendations for the management of ankylosing spondylitis. Ann Rheum Dis 2011;70:896-904.

9 Boersma JW. Retardation of ossification of the lumbar vertebral column in ankylosing spondylitis by means of phenylbutazone. Scand J Rheumatol 1976;5:60-4.

10 Wanders A, Heijde D, Landewe R, et al. Nonsteroidal antiinflammatory drugs reduce radiographic progression in patients with ankylosing spondylitis: a randomized clinical trial. Arthritis Rheum 2005;52:1756-65.

11 Dougados M, Simon P, Braun J, et al. ASAS recommendations for collecting, analysing and reporting NSAID intake in clinical trials/epidemiological studies in axial spondyloarthritis. Ann Rheum Dis 2011;70:249-51.
12 Poddubnyy $D$, Rudwaleit $M$, Haibel $H$, et al. Effect of non-steroidal anti-inflammatory drugs on radiographic spinal progression in patients with axial spondyloarthritis: results from the German Spondyloarthritis Inception Cohort. Ann Rheum Dis 2012;71:1616-22.

13 van der Heijde D, Landewe R. Selection of a method for scoring radiographs for ankylosing spondylitis clinical trials, by the Assessment in Ankylosing Spondylitis Working Group and OMERACT. J Rheumatol 2005;32:2048-9.

14 Brunner E, Domhof S, Langer F. Nonparametric analysis of longitudinal data in factorial designs. New York: Wiley, 2002.

15 Baraliakos X, Listing J, Rudwaleit M, et al. Progression of radiographic damage in patients with ankylosing spondylitis: defining the central role of syndesmophytes. Ann Rheum Dis 2007;66:910-15.

16 Poddubnyy D, Haibel H, Listing J, et al. Baseline radiographic damage, elevated acute-phase reactant levels, and cigarette smoking status predict spinal radiographic progression in early axial spondylarthritis. Arthritis Rheum 2012;64:1388-98.

17 Kroon F, Landewe R, Dougados M, et al. Continuous NSAID use reverts the effects of inflammation on radiographic progression in patients with ankylosing spondylitis. Ann Rheum Dis 2012;71:1623-9.

18 Maksymowych WP, Chiowchanwisawakit P, Clare T, et al. Inflammatory lesions of the spine on magnetic resonance imaging predict the development of new syndesmophytes in ankylosing spondylitis: evidence of a relationship between inflammation and new bone formation. Arthritis Rheum 2009;60:93-102.

19 Vane SJ. Differential inhibition of cyclooxygenase isoforms: an explanation of the action of NSAIDs. J Clin Rheumatol 1998;4(5 Suppl):s3-10.

20 Krischak GD, Augat P, Blakytny R, et al. The non-steroidal anti-inflammatory drug diclofenac reduces appearance of osteoblasts in bone defect healing in rats. Arch Orthop Trauma Surg 2007;127:453-8.

21 Simon AM, Manigrasso MB, O'Connor JP. Cyclo-oxygenase 2 function is essential for bone fracture healing. J Bone Miner Res 2002;17:963-76.

22 Romano CL, Duci D, Romano D, et al. Celecoxib versus indomethacin in the prevention of heterotopic ossification after total hip arthroplasty. J Arthroplasty 2004;19:14-18.

23 Saudan M, Saudan P, Perneger T, et al. Celecoxib versus ibuprofen in the prevention of heterotopic ossification following total hip replacement: a prospective randomised trial. J Bone Joint Surg Br 2007;89:155-9.

24 Zweers MC, de Boer TN, van Roon J, et al. Celecoxib: considerations regarding its potential disease-modifying properties in osteoarthritis. Arthritis Res Ther 2011;13:239.

25 Mastbergen SC, Jansen NW, Bijlsma JW, et al. Differential direct effects of cyclo-oxygenase-1/2 inhibition on proteoglycan turnover of human osteoarthritic cartilage: an in vitro study. Arthritis Res Ther 2006;8:R2.

26 Chang JK, Li CJ, Liao HJ, et al. Anti-inflammatory drugs suppress proliferation and induce apoptosis through altering expressions of cell cycle regulators and pro-apoptotic factors in cultured human osteoblasts. Toxicology 2009;258:148-56.

27 Tegeder I, Pfeilschifter J, Geisslinger G. Cyclooxygenase-independent actions of cyclooxygenase inhibitors. FASEB J 2001;15:2057-72.

28 Schonthal AH. Direct non-cyclooxygenase-2 targets of celecoxib and their potential relevance for cancer therapy. Br J Cancer 2007;97:1465-8.

29 Song $\mathrm{IH}$, Poddubnyy DA, Rudwaleit $\mathrm{M}$, et al. Benefits and risks of ankylosing spondylitis treatment with nonsteroidal antiinflammatory drugs. Arthritis Rheum 2008:58:929-38. 